\title{
Cigarette Smoking Impairs Sperm Bioenergetics
}

\author{
Kazim R. Chohan, Shawky Z. A. Badawy \\ Departments of Pathology and Obstetrics \& Gynecology, State University of New York, Upstate Medical \\ University, Syracuse, New York, USA
}

\begin{abstract}
Objective: The growing consensus on the negative impact of cigarette smoking on fertility prompted us to compare the rate of sperm respiration in smokers and non-smokers.

Materials and Methods: Semen samples from 20 smokers and 58 non-smokers consulting at the andrology laboratory for fertility evaluation were used. Smoking was defined as consumption of at least a half a pack per day. A phosphorescence analyzer that measures $\mathrm{O}_{2}$ concentration in sperm suspensions as function of time was used to determine the rate of respiration. In a sealed vial, the rate of sperm respiration $(\mathrm{k})$ was defined as $-\mathrm{d}\left[\mathrm{O}_{2}\right] / \mathrm{dt}$; where $\left[\mathrm{O}_{2}\right]$ was obtained from the phosphorescence decay rate of a palladium phosphor. $\left[\mathrm{O}_{2}\right]$ in solutions containing sperm and glucose declined linearly with time, showing the kinetics of $\mathrm{O}_{2}$ consumption was zero-order. Inhibition of $\mathrm{O}_{2}$ consumption by cyanide confirmed the oxidations that occurred in the sperm mitochondrial respiratory chain.

Results: There were no differences $(\mathrm{p}>0.28)$ between smokers and non-smokers for ejaculate volume, motility, concentration, normal morphology, viability and hypo-osmotic swelling test. The rate (mean $\pm \mathrm{SD}$, in $\mu \mathrm{M} \mathrm{O}_{2} / \mathrm{min} / 10^{8} \mathrm{sperm}$ ) of sperm mitochondrial $\mathrm{O}_{2}$ consumption in the smokers was $0.96 \pm 0.58$ and in the non-smokers $1.39 \pm 0.67(\mathrm{p}=0.004)$. Conclusions: The rate of sperm respiration was significantly lower in smokers. This negative impact of cigarette smoking on sperm aerobic metabolism may, in part, explain the lower rate of fertility in smokers.
\end{abstract}

Key words: male infertility; smoking; sperm; respiration; human

Int Braz, J Urol. 2010; 36: 60-5

\section{INTRODUCTION}

The detection of nicotine, and its major metabolite cotinine, in the seminal plasma of smokers showed that the tobacco compounds cross the bloodtestis barrier and create a toxic environment for the spermatozoa $(1,2)$. Toxic components in the cigarette smoke can disrupt the testicular microcirculation and cause DNA or chromosomal damage in germinal cells $(3,4)$. The combustion also reduces semen volume, sperm concentration, motility and normal morphology
(5-12). Cigarette smoking also decreases fertilizing capacity of the sperm $(13,14)$. Moreover, oligozoospermia has been linked to prenatal tobacco exposure in a dose-dependent manner (15). Smokers have more oxidative DNA damage and aneuploidy in their sperm than non-smokers (16-19). These observations confirm the deleterious effects of cigarette smoking on human fertility.

Cigarette smoking is still a major health dilemma, especially in "reproductive age" men and women. In a recent survey in the United States, 30- 
$35 \%$ of these individuals smoke cigarettes (20). The growing consensus on the negative impact of cigarette smoking on fertility prompted us to compare the rate of sperm respiration in smokers and non-smokers. For this purpose, we used a phosphorescence analyzer that accurately measures $\mathrm{O}_{2}$ concentration as function of time in sperm suspensions $(21,22)$. In this study, we evaluated the effect of cigarette smoking on sperm bioenergetics.

\section{MATERIALS AND METHODS}

\section{Chemicals and Solutions}

Pd (II) complex of meso-tetra-(4-sulfonatophenyl)-tetrabenzoporphyrin (Pd phosphor sodium salt) was purchased from Porphyrin Products (Logan, UT). Modified Human Tubal Fluid (mHTF), containing $97.8 \mathrm{mM} \mathrm{NaCl}, 4.69 \mathrm{mM} \mathrm{KCl}, 0.2 \mathrm{mM} \mathrm{MgSO}_{4}$, $0.37 \mathrm{mM} \mathrm{KH}_{2} \mathrm{PO}_{4}, 2.04 \mathrm{mM} \mathrm{CaCl}_{2}, 4.0 \mathrm{mM} \mathrm{NaHCO}_{3}$, $21 \mathrm{mM}$ HEPES, $2.78 \mathrm{mM}$ glucose, $0.33 \mathrm{mM} \mathrm{Na}$ pyruvate, $21.4 \mathrm{mM}$ Na lactate, $10 \mu \mathrm{g} / \mathrm{mL}$ gentamicin sulfate, $5 \mathrm{mg} / \mathrm{L}$ phenol red and $0.5 \%$ human serum albumin) was purchased from Irvine Scientific (Santa Ana, CA). The remaining reagents were obtained from Sigma-Aldrich.(Saint Louis, MO) Pd phosphor solution $(2 \mathrm{mM})$ was made by dissolving the powder at $2.5 \mathrm{mg} / \mathrm{mL}$ in $\mathrm{dH}_{2} \mathrm{O}$ and stored at $-20^{\circ} \mathrm{C}$ in small aliquots. $\mathrm{NaCN}(1.0 \mathrm{M})$ was made fresh in $\mathrm{dH}_{2} \mathrm{O}$, and the $\mathrm{pH}$ was adjusted to $\sim 7$ with $12 \mathrm{~N} \mathrm{HCl}$.

\section{Study Population}

Seventy-eight (20 smokers and 58 non-smokers) patients attending the Andrology Laboratory for fertility testing were included in this study. The study was approved by the Institutional Review Board for protection of human subjects and informed consent was obtained from each patient. The average for number of cigarettes smoked per day was $11.6 \pm 6.1$ (mean $\pm \mathrm{SD}$ ). A single semen sample with a sexual abstinence period between 2-7 days was collected for each patient. The samples were evaluated according to World Health Organization 1999 criteria. Semen samples were allowed to liquefy at $37^{\circ} \mathrm{C}$ for $30 \mathrm{~min}$ utes and only samples with $\leq 5$ amorphous cells per hpf were selected. Additionally, peroxidase staining was performed on each sample to detect leukocytes. Only samples with negligible or without any leukocytes were used. Samples with similar semen parameters for smokers and non-smokers were selected for $\mathrm{O}_{2}$ measurement to rule out the contribution of other variables. To measure respiration, an aliquot was diluted (2-fold) in mHTF and centrifuged at $25^{\circ} \mathrm{C}$ $(300 \mathrm{xg})$ for $10 \mathrm{~min}$. within one hour after collection. The pellets were suspended at $\sim 10^{8}$ sperm per $\mathrm{mL}$ in mHTF supplemented with $2 \mu \mathrm{M}$ Pd phosphor. The sample was immediately transferred to $1-\mathrm{mL}$ glass vial, sealed and placed in the instrument for $\mathrm{O}_{2}$ measurement.

\section{Cellular Respiration}

$\left[\mathrm{O}_{2}\right]$ in the sperm suspensions was determined as function of time, using the Pd phosphor. The phosphorescence decay $(1 / \tau)$ of the probe was exponential, with $\tau$ being linear in $\left[\mathrm{O}_{2}\right]$, according to $\tau^{\circ} / \tau=1+\tau^{\circ} \mathrm{k}_{\mathrm{q}}$ $\left[\mathrm{O}_{2}\right] ; \tau$, lifetime in the presence of $\mathrm{O}_{2} ; \tau^{\circ}$, lifetime in the absence of $\mathrm{O}_{2}$; and $\mathrm{k}_{\mathrm{q}}$, second-order $\mathrm{O}_{2}$ quenching constant. Samples were exposed to light flashes (10 per sec) from a pulsed light-emitting diode array with peak output at $625 \mathrm{~nm}$. Emitted light was detected by a Hamamatsu photomultiplier tube after passing through a wide-band interference filter centered at $800 \mathrm{~nm}$. The amplified phosphorescence decay was digitized at a rate of $1 \mathrm{MHz}$ by an $\mathrm{A} / \mathrm{D}$ converter. The values of $\tau$ were determined in a series of ascorbate plus ascorbate oxidase solutions, simultaneously with electrochemical measurements of $\left[\mathrm{O}_{2}\right]$. A plot of $1 / \tau$ vs. $\left[\mathrm{O}_{2}\right]$ was linear; the value of the quenching constant $\mathrm{k}_{\mathrm{q}}$ (the slope) was $96.1 \pm 1.2 \mu \mathrm{M}^{-1} \mathrm{~s}^{-1}$ and $1 / \tau^{\circ}$ (the intercept) $10087 \pm 156 \mathrm{~s}^{-1}$ (21).

For each run, $1.0 \mathrm{~mL}$ of the sperm suspension was placed in 1-mL sealed glass vial. The changes in $\left[\mathrm{O}_{2}\right]$ with time were measured at $37^{\circ} \mathrm{C}(21,22)$. Mixing was accomplished with parylene-coated stirring bar. Rates of respiration were the negative of the slopes of $\left[\mathrm{O}_{2}\right]$ vs. $\mathrm{t}$ (zero-order rate constant, $\mathrm{k}$, in $\mu \mathrm{M} \mathrm{O}_{2}$ $\mathrm{min}^{-1}$ per $\left.10^{8} \mathrm{sperm}\right)$. Representative runs are shown in Figure-1. 


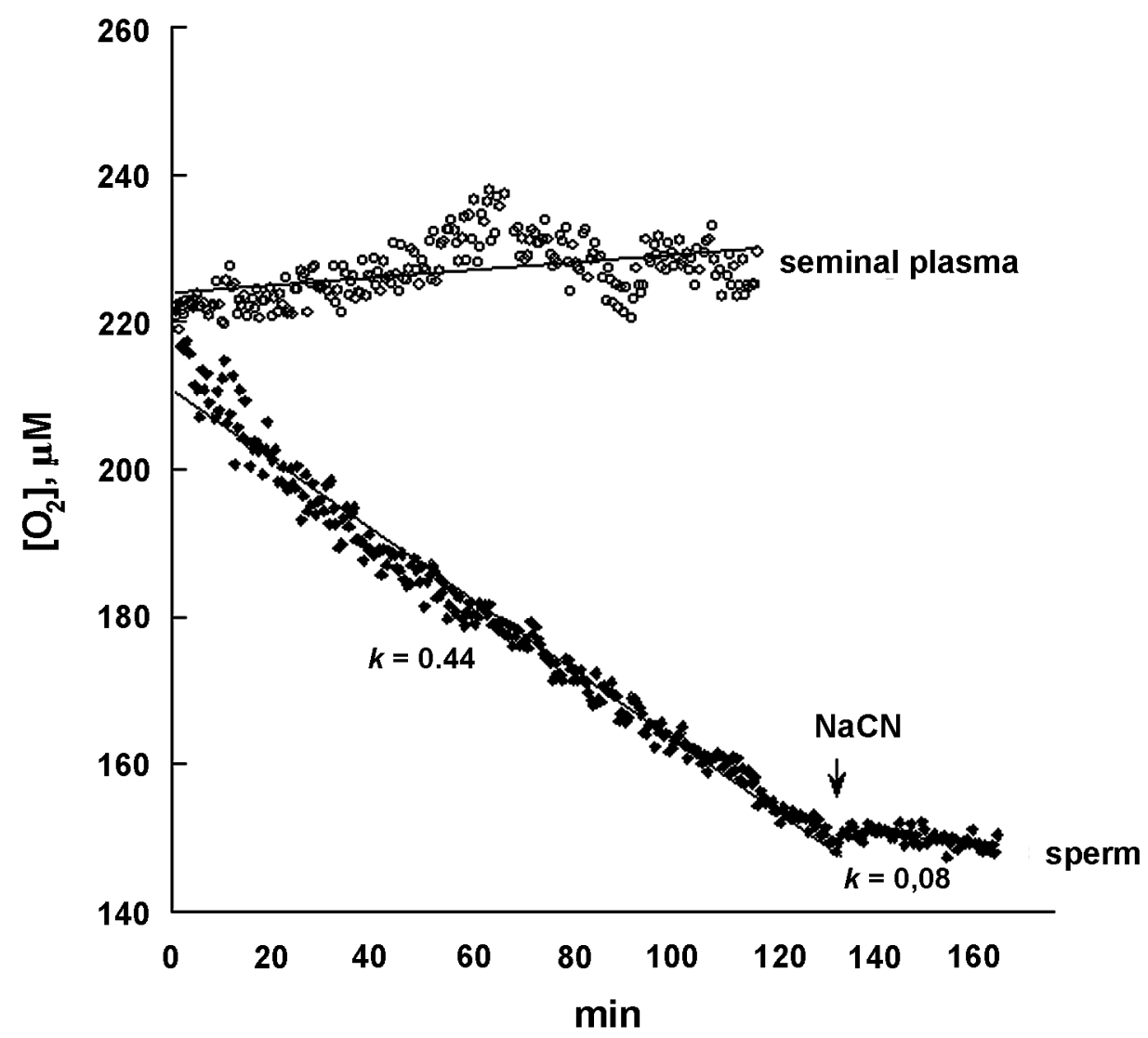

Figure 1 - Representative plot of $\mathrm{O}_{2}$ consumption as function of time in sperm and seminal plasma from a smoker. $\mathrm{O}_{2}$ consumption was not observed in the seminal plasma without sperm (open circles). [ $\left.\mathrm{O}_{2}\right]$ declined linearly with time in the sperm suspension (closed diamonds). The decline in $\left[\mathrm{O}_{2}\right]$ was inhibited by $87 \%$ after the addition of $\mathrm{NaCN}$, confirming the oxidations occurred in the sperm mitochondrial respiratory chain. Best-fit curves $\left(r^{2}=0.978\right)$ and values of $k\left(\mu M \mathrm{O}_{2} \mathrm{~min}^{-1}\right.$ per $10^{8}$ sperm) are shown.

\section{Statistical Analysis}

The data for semen parameters between smokers and non-smokers was compared using Student t-test. The Mann-Whitney rank sum test was used to compare respiration rate in sperm.

\section{RESULTS}

Semen parameters and sperm respiration rates for smokers and non-smokers are summarized in Table-1. No differences between smokers and non-smokers were observed for the ejaculate volume, motility, concentration, normal morphology, viability and hypo-osmotic swelling (HOS) test ( $\mathrm{p}>0.28$ ). However, the rate of sperm respiration (mean $\pm \mathrm{SD}, \mathrm{k}$, in $\mu \mathrm{M} \mathrm{O}_{2} / \mathrm{min} / 10^{8}$ sperm) in the non-smokers was 1.39 \pm 0.67 and in the smokers $0.96 \pm 0.58(\mathrm{p}=0.004)$.

\section{COMMENTS}

Our results show that cigarette smoking lowers sperm mitochondrial $\mathrm{O}_{2}$ consumption (sperm respiration), Table-1. The mechanism for this inhibitory effect in sperm remains unclear. Cigarette smoke yields many toxic compounds which have inhibitory or stimulatory effects on various cells and body functions, one of which is total inhibition of 
Table 1 -Sperm parameters and rates of respiration in smokers and non-smokers.

\begin{tabular}{lcc}
\hline & $\begin{array}{c}\text { Smokers } \\
(\mathrm{N}=20)\end{array}$ & $\begin{array}{c}\text { Non-smokers } \\
(\mathrm{N}=58)\end{array}$ \\
\hline Ejaculate volume $(\mathrm{mL})$ & $3.2 \pm 1.3$ & $3.6 \pm 1.4$ \\
Total motility $(\%)$ & $62.3 \pm 8.4$ & $61.8 \pm 9.1$ \\
Progressive motility $(\%)$ & $50.2 \pm 12.1$ & $48.7 \pm 10.2$ \\
Sperm concentration $\left(10^{6} / \mathrm{mL}\right)$ & $125 \pm 73$ & $134 \pm 83$ \\
Normal morphology $(\%)$ & $21.1 \pm 13.4$ & $20.4 \pm 10.0$ \\
Viability (\%) & $55.8 \pm 10.4$ & $55.9 \pm 10.8$ \\
HOS (\%) & $71.1 \pm 7.3$ & $72.0 \pm 8.9$ \\
Rate of respiration & $0.96 \pm 0.58$ & $1.39 \pm 0.67$ \\
\hline
\end{tabular}

The values are mean $\pm S D$. The $p$ value between smokers and non-smokers for the rate of respiration (in $\mu M O_{2} / \mathrm{min} / 10^{8} \mathrm{sperm}$ ) was 0.004. No statistical differences were observed for the remaining parameters. HOS = hypo-osmotic swelling.

ciliary movement at bronchial level (23). The decreased cellular respiration observed in smokers can occur due to toxic compounds in the cigarette smoke. These include nicotine, cadmium, carbon monoxide, hydrogen cyanide, ammonia volatile hydrocarbons, alcohol, aldehydes and ketones, etc.

No differences were observed for conventional semen parameters between smokers and non-smokers in the present study. Similar findings have been observed previously (24). Significant negative impact of cigarette smoking on semen quality; however, has also been reported (5-12). Lower sperm mitochondrial function (respiration) in smokers may be a consequence of sperm exposure to smoke-related toxins present in seminal plasma. The impact of these toxins on mitochondrial function seems non-reversible because washed sperm devoid of seminal plasma were used in this study. Irreversible degenerative damage to the architectural elements of the sperm tail or axoneme in smokers has been previously observed (25). This ultra structural damage includes the absence of one or more fiber doublets, central fibers, and coarse outer fibers. The mitochondria are a principal part of sperm tail therefore, such ultra structural damage in the tail region can also result in impaired mitochondrial function. Exposure of non-smoker's sperm to the seminal plasma of a smoker resulted in significantly reduced motility and membrane functional integrity (26). Oxidative stress produced in seminal plasma due to smoking can be another factor for this phenomenon (27).
In summary, our results show a significantly lower sperm mitochondrial $\mathrm{O}_{2}$ consumption rate in smokers. Further studies are needed to identify those constituents of cigarette smoke that mediate this effect.

\section{ACKNOWLEDGEMENTS}

We are grateful for the support of Ms. Violeta Cuenca and Mrs. Crystal Kling for this work.

\section{CONFLICT OF INTEREST}

None declared.

\section{REFERENCES}

1. Pacifici R, Altieri I, Gandini L, Lenzi A, Pichini S, Rosa M, et al.: Nicotine, cotinine, and trans-3-hydroxycotinine levels in seminal plasma of smokers: effects on sperm parameters. Ther Drug Monit. 1993; 15: 358-63.

2. Vine MF, Hulka BS, Margolin BH, Truong YK, Hu PC, Schramm MM, et al.: Cotinine concentrations in semen, urine, and blood of smokers and nonsmokers. Am J Public Health. 1993; 83: 1335-8.

3. Collin O, Kilter S, Bergh A: Tobacco smoke disrupts testicular microcirculation in the rat. Int J Androl. 
1995; 18: 141-5. Erratum in: Int J Androl. 1995; 18: 230.

4. Zenzes MT: Smoking and reproduction: gene damage to human gametes and embryos. Hum Reprod Update. 2000; 6: 122-31.

5. Evans HJ, Fletcher J, Torrance M, Hargreave TB: Sperm abnormalities and cigarette smoking. Lancet. 1981; 1: 627-9.

6. Vogt HJ, Heller WD, Borelli S: Sperm quality of healthy smokers, ex-smokers, and never-smokers. Fertil Steril. 1986; 45: 106-10.

7. Rantala ML, Koskimies AI: Semen quality of infertile couples--comparison between smokers and non-smokers. Andrologia. 1987; 19: 42-6.

8. Holzki G, Gall H, Hermann J: Cigarette smoking and sperm quality. Andrologia. 1991; 23: 141-4.

9. Künzle R, Mueller MD, Hänggi W, Birkhäuser MH, Drescher H, Bersinger NA: Semen quality of male smokers and nonsmokers in infertile couples. Fertil Steril. 2003; 79: 287-91.

10. Pasqualotto FF, Sobreiro BP, Hallak J, Pasqualotto EB, Lucon AM: Cigarette smoking is related to a decrease in semen volume in a population of fertile men. BJU Int. 2006; 97: 324-6.

11. Ramlau-Hansen $\mathrm{CH}$, Thulstrup AM, Aggerholm AS, Jensen MS, Toft G, Bonde JP: Is smoking a risk factor for decreased semen quality? A cross-sectional analysis. Hum Reprod. 2007; 22: 188-96.

12. Gaur DS, Talekar M, Pathak VP: Effect of cigarette smoking on semen quality of infertile men. Singapore Med J. 2007; 48: 119-23.

13. Sofikitis N, Takenaka M, Kanakas N, Papadopoulos $\mathrm{H}$, Yamamoto Y, Drakakis $\mathrm{P}$, et al.: Effects of cotinine on sperm motility, membrane function, and fertilizing capacity in vitro. Urol Res. 2000; 28: 370-5.

14. Zitzmann M, Rolf C, Nordhoff V, Schräder G, Rickert-Föhring M, Gassner P, et al.: Male smokers have a decreased success rate for in vitro fertilization and intracytoplasmic sperm injection. Fertil Steril. 2003; 79 (Suppl 3): 1550-4.

15. Jensen MS, Mabeck LM, Toft G, Thulstrup AM, Bonde JP: Lower sperm counts following prenatal tobacco exposure. Hum Reprod. 2005; 20: 2559-66.

16. Rubes J, Lowe X, Moore D 2nd, Perreault S, Slott V, Evenson D, et al.: Smoking cigarettes is associated with increased sperm disomy in teenage men. Fertil Steril. 1998; 70: 715-23.

17. Shi Q, Ko E, Barclay L, Hoang T, Rademaker A, Martin R: Cigarette smoking and aneuploidy in human sperm. Mol Reprod Dev. 2001; 59: 417-21.

18. Horak S, Polanska J, Widlak P: Bulky DNA adducts in human sperm: relationship with fertility, semen quality, smoking, and environmental factors. Mutat Res. 2003; 537: 53-65.

19. Sepaniak S, Forges T, Gerard H, Foliguet B, Bene MC, Monnier-Barbarino P: The influence of cigarette smoking on human sperm quality and DNA fragmentation. Toxicology. 2006; 223: 54-60.

20. Practice Committee of the American Society for Reproductive Medicine: Smoking and infertility. Fertil Steril. 2006; 86 (5 Suppl 1): S172-7.

21. Tao Z, Withers HG, Penefsky HS, Goodisman J, Souid AK: Inhibition of cellular respiration by doxorubicin. Chem Res Toxicol. 2006; 19: 1051-8.

22. Badawy ZS, Chohan KR, Whyte DA, Penefsky HS, Brown OM, Souid AK: Cannabinoids inhibit the respiration of human sperm. Fertil Steril. 2009; 91: 2471-6.

23. Marchese-Ragona SP, Johnson KA: Structural and biochemical studies of the dynen ATPase. In: Gagnon C (eds.), Controls of Sperm Motility: Biological and Clinical Aspects. CRC Press, Boca Raton. 1990; pp. 203.

24. Trummer H, Habermann H, Haas J, Pummer K: The impact of cigarette smoking on human semen parameters and hormones. Hum Reprod. 2002; 17: 1554-9.

25. Zavos PM, Correa JR, Karagounis CS, Ahparaki A, Phoroglou C, Hicks CL, et al.: An electron microscope study of the axonemal ultrastructure in human spermatozoa from male smokers and nonsmokers. Fertil Steril. 1998; 69: 430-4.

26. Zavos PM, Correa JR, Antypas S, Zarmakoupis-Zavos $\mathrm{PN}$, Zarmakoupis CN: Effects of seminal plasma from cigarette smokers on sperm viability and longevity. Fertil Steril. 1998; 69: 425-9.

27. Saleh RA, Agarwal A, Sharma RK, Nelson DR, Thomas AJ Jr: Effect of cigarette smoking on levels of seminal oxidative stress in infertile men: a prospective study. Fertil Steril. 2002; 78: 491-9.

Accepted after revision:

August 17, 2009

Correspondence address:

Dr. Kazim R. Chohan

SUNY Upstate Medical University

750 East Adams Street

Syracuse, NY, 13210, USA

Fax: + 1315 464-6711

E-mail: chohank@upstate.edu 


\section{EDITORIAL COMMENT}

Smoking is a lifestyle hazard for both active and passive smokers (1). Although sperm concentrations, motility, and/or morphology are often reduced compared to results observed in non-smokers, they often remain within the normal range (2). In this article, no differences were found between smokers and non-smokers for these parameters. However, it does show a negative impact of smoking on sperm mitochondrial function. Although sperm mitochondrial $\mathrm{O} 2$ consumption is not a routine test, as a functional test, it may represent a predictive value for smoking men with normal sperm count aiming pregnancy. In accordance with literature, spermatozoa from smokers have reduced fertilizing capacity and embryos display lower implantation rates (3).

As discussed in the article, the mechanism for the inhibitory effect of smoking in sperm mitochondrial $\mathrm{O} 2$ respiration remains unclear. This decreased cellular respiration can occur due to toxic compounds (1), to oxidative stress (4) or to both. According to Gaur et al., direct exposure of spermatozoa to the toxins in cigarette smoke probably tilts the delicate balance of reactive oxygen species that are produced by spermatozoa for their special functions like decapitation (1).

In conclusion, couples in reproductive age should be strongly discouraged to smoke (3).

\section{REFERENCES}

1. Gaur DS, Talekar M, Pathak VP: Effect of cigarette smoking on semen quality of infertile men. Singapore Med J. 2007; 48: 119-23.

2. The Practice Committee of the American Society for Reproductive Medicine: Smoking and infertility. Fertil Steril. 2008; 90: S254-9.

3. Soares SR, Melo MA: Cigarette smoking and reproductive function. Current Opin Obstet Gynecol. 2008; 20: 281-91.

4. Saleh RA, Agarwal A, Sharma RK, Nelson DR, Thomas AJ Jr: Effect of cigarette smoking on levels of seminal oxidative stress in infertile men: a prospective study. Fertil Steril. 2002; 78: 491-9.

Dr. Renato Fraietta \&
Dr. Agnaldo P. Cedenho
Department of Surgery
Division of Urologic Surgery
Federal University of Sao Paulo, UNIFESP
Sao Paulo, SP, Brazil
E-mail: fraietta@renatofraietta.med.br

Dr. Renato Fraietta \& Department of Surgery Sao Paulo, UNIFESP E-mail:fraietta@renatofraietta.med.br 